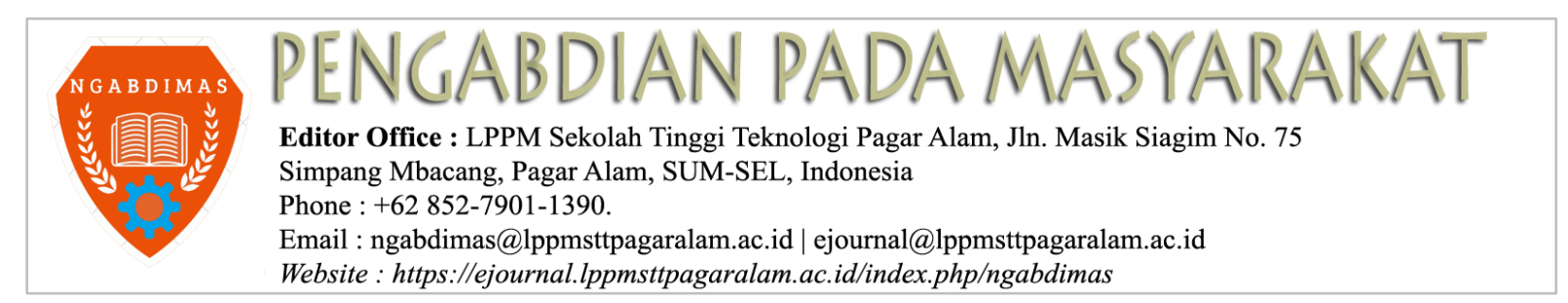

\title{
Pelatihan Editing Photo Dengan Adobe Photosop Di SMA Negeri 3 Pagar Alam
}

\author{
Siti Aminah ${ }^{1}$, Sasmita $^{2}$ \\ Program Studi Teknik Informatika; Sekolah Tinggi Teknologi Pagaralam (STTP) \\ Jl. M. Siagim No.75 Kel. Karang Dalo, Dempo Tengah, Kota Pagar Alam \\ Telp/Fax: (0730) 621916 \\ e-mail: gosupeta@gmail.com¹. sasmitha661@.gmail.com²
}

\begin{abstract}
Abstrak
Edit foto merupakan softskills yang berusaha diberikan kepada siswa terutama alumni SMAN 3 Pagar Alam sebagai tambahan ilmu agar siswa calon alumni memiliki nilai tambah ketika ada di masyarakat, sehingga dengan adanya penambahan program softskills ini membuat alumni SMAN 3 Pagar Alam memiliki nilai tambah sehingga alumni memiliki kepercayaan diri ketika terjun ke masyarakat. Metode pelatihan yang dilakukan dengan cara penjelasan secara langsung, berikutnya dilakukan praktek secara langsung, agar peserta pelatihan berjalan dengan baik sebelum pelatihan dilakukan tes terlebih dahulu untuk mengetahui pemahaman peserta terhadap editing foto, dan hasilnya peserta belum penah melakukan editing foto dengan photoshop, setelah pelatihan dilakukan lagi tes untuk mengetahui tingkat keberhasilan pada pelatihan yang dilakukan dan hasilnya seluruh peserta pelatihan mampu melakukan editing foto menggunakan software photoshop dengan hasil yang baik.
\end{abstract}

Kata kunci-Edit, Siswa, SMAN, Pelatihan, Foto, Photoshop, Edit.

\section{PENDAHULUAN.}

Pada saat ini perkembangan teknologi informasi dan komunikasi khususnya teknologi yang mendukung terlaksananya kegiatan (pendukung) pembelajaran saat ini sangat banyak dan menawarkan kemudahan sesuai ke unggulan masing-masing, salah satunya adalah adobe photoshop yang bisa di manfaatkan sebagai sarana pembuatan aplikasi pengolahan data photo. Media ini sangat banyak sekali digunakan di sebagai sarana pengolahan data yang sangat familiar, terutama diaplikasikan untuk pengolahan data foto dan video.

Penggunaan adobe photoshop sebagai media/sarana pembuatan aplikasi pengolahan data photo ini sangat di sarankan karena memiliki menu-menu yang sesuai dengan standar penulisan yang di sarankan oleh para ahli yang kompeten, sehingga pada saat penyusunan pada adobe photshop ini pembuat aplikasi tinggal klik menu-menu yang di maksud maka di dapat hasil gambar (hitungan/pengolah data) yang baik (standar), selain itu adobe photoshop merupakan software pengolah data yang mudah, selain itu apa bila ingin meng-upgrade, atau mengganti ke versi terbaru developer menyediakan dengan mudah karena user yang menggunakan sangat banyak.

Pemaparan diatas dituntut agar para siswa SMAN 3 Kota Pagar Alam dan pemuda harus selalu meningkatkan kualitas pembelajaran dengan menggunakan semua resource terkait, sehingga dipandang perlu untuk diadakan pelatihan pembuatan aplikasi pengolahan data photo ini. Berdasarkan informasi yang diperoleh dari para siswa siswi peserta SMAN 3 Pagar Alam masalah yang dihadapi dapat diidentifikasikan sebagai berikut.

1. Para mahasiswa baru belum terlalu memahami teknik edit photo.

2. Para mahasiswa belum dapat membuat aplikasi pengolah data photo dengan baik. 
Sehingga pelatihan editing video dan foto ini menjadi softskills tambahan yang sangat baik bagi peserta pelatihan, tidak hanya memahami teori pelajaran umum saja, tetapi ini menjadi nilai tambah bagi alumni SMAN 3 Kota Pagar Alam, sehingga masyarakat menjadi semakin yakin dan percaya kepada SMAN 3 Kota Pagar Alam dan mau masuk jadi peserta didik yang baru.

\section{METODE.}

Pengabdian dilakukan dengan pelatihan secara langsung dengan menyimak (menonton) bersama, membaca bersama (modul pelatihan), memahami tools aplikasi (Software) dan berinteraksi secara langsung (Aplikatif) dengan software. Dan pada awal dan akhir kegiatan dilakukan pemantauan atau tes untuk mengefektifkan kegiatan yang dilakukan sehingga peserta benar-benar memahami materi yang dilatihkan.

\subsection{Pengabdian Pada Masyarakat (PkM).}

Program kerja kegiatan pengabdian kepada masyarakat (PkM) merupakan kegiatan yang bertujuan untuk membantu masyarakat dalam beraktivitas tanpa mengharapkan imbalan dalam bentuk apapun. Secara umum program ini dirancang oleh Perguruan Tinggi (PT) yang ada di Indonesia untuk memberikan kontribusi bagi bangsa, khususnya dalam mengembangkan kesejahteraan dan kemajuan masyarakat. Kegiatan Pengabdian kepada Masyarakat (PkM) merupakan satu bagian dari Tri Dharma Perguruan Tinggi. Yang mana bentuk-bentuk kegiatan Pengabdian Masyarakat, berupa: Bakti Sosial dan Mengajar. Tujuan Pengabdian Masyarakat (PkM) di Perguruan Tinggi, yaitu:

1. Melaksanakan program kegiatan yang dapat mengentaskan masyarakat tersisih (preferential option for the poor) pada semua strata, yaitu masyarakat yang tersisih secara ekonomi, politik, sosial, dan budaya;

2. Menciptakan daya inovasi teknologi informasi mendorong pembangunan ekonomi dengan melakukan komersialisasi hasil penelitian, yang dilakukan;

3. Memberikan solusi berdasarkan hasil kajian akademik yang mendalam atas kebutuhan, tantangan atau persoalan dihadapi masyarakat, baik secara langsung maupun tidak langsung;

4. Melaksanakan alih teknologi, ilmu dan seni kepada masyarakat untuk pengembangan martabat manusia dan kelestarian sumber daya alam yang ada pada lingkungan masyarakat.

\subsection{Multimedia.}

Multimedia merupakan aplikasi komputer menyajikan dan menggabungkan teks, suara, gambar, animasi, audio \& video dengan alat bantu (tool) dan koneksi (link) sehingga user bisa melakukan navigasi, berinteraksi, berkarya dan berkomunikasi. Multimedia sering dimanfaatkan pada dunia informatika. Selain dunia informatika, multimedia juga diadopsi dunia game, dan juga untuk membuat website, bahkan saat ini dunia pendidikan sudah mengikuti mengaplikasikan multimedia untuk kelancaran pemberlajaran dalam kelas.

Multimedia sendiri berasal dari kata 'multi' dan 'media'. Multi artinya banyak, dan media berarti tempat, sarana atau alat yang digunakan untuk menyampaikan informasi. Maka berdasarkan kata 'multimedia' bisa dirumuskan sebagai wadah atau penyatuan beberapa media, kemudian didefinisikan sebagai elemen pembentukan multimedia. Elemen tersebut seperti teks, gambar, suara, animasi \& video. Multimedia merupakan suatu konsep dan teknologi baru bidang teknologi informasi (TI), di mana informasi dalam bentuk teks, gambar, suara, animasi, dan video disatukan dalam komputer untuk di simpan, diproses dan disajikan baik secara liner maupun interaktif. Oleh itu, dengan menggabungkan seluruh elemen multimedia tersebut menjadikan informasi dalam bentuk multimedia yang bisa diterima indera penglihatan dan pendengaran, lebih mendekati bentuk asli dalam dunia sebenarnya. Multimedia enteraktif apabila suatu aplikasi terdapat seluruh elemen multimedia yang ada dan user diberi keputusan atau kemampuan untuk mengawal dan menghidupkan elemen tersebut. Pengertian Multimedia Menurut Para Ahli, sebagai berikut:

a. Menurut McCormick (1996), Multimedia adalah kombinasi tiga elemen, suara, gambar, dan

b. Menurut Rosch (1996), Multimedia sebagai kombinasi dari komputer dan video.

c. Menurut Gumelar (2014), Multimedia adalah penggunaan komputer untuk menyajikan dan menggabungkan teks, animasi, suara, gambar dan video dengan tools (alat bantu) dan link sehingga pengguna dapat melakukan navigasi, interaksi, berkarya dan berkomunikasi. 
Multimedia untuk dunia pendidikan dan bisnis. Di dunia pendidikan, multimedia digunakan sebagai media pengajaran, baik dalam kelas maupun secara sendiri-sendiri atau otodidak. Di dunia bisnis, multimedia digunakan sebagai media profil perusahaan, profil produk, bahkan sebagai media kios informasi dan pelatihan dalam sistem e-learning. Pada awalnya multimedia hanya mencakup media yang menjadi konsumsi indra penglihatan (gambar diam, teks, gambar gerak video, dan gambar gerak rekaan/animasi), dan konsumsi indra pendengaran (suara) dan juga berupa ( berwujud). Dalam perkembangannya multimedia mencakup juga kinetik (gerak) dan bau yang merupakan konsumsi indra penciuman. Multimedia mulai memasukkan unsur kinetik sejak diaplikasikan pada pertunjukan film 3 dimensi, digabungkan dengan gerakan pada kursi tempat duduk penonton. Kinetik, dan film 3 dimensi membangkitkan sense realistis.

Untuk bau mulai menjadi bagian dari multimedia sejak ditemukan teknologi reproduksi bau melalui telekomunikasi. Perangkat input pendeteksi bau, seorang operator bisa mengirimkan hasil digitizing bau tersebut melalui internet. Komputer penerima harus menyediakan perangkat output berupa mesin reproduksi bau. Mesin reproduksi bau ini mencampurkan berbagai jenis bahan bau yang setelah dicampur menghasilkan output berupa bau mirip dengan data dikirim dari internet. Dengan menganalogikan dengan printer, alat ini menjadikan feromon bau sebagai pengganti tinta. Output bukan berupa cetakan melainkan aroma.

\section{PERKEMBANGAN MULTIMEDIA}

Tahun 70-an, penggunaan mikro komputer di rumah dan pejabat telah dapat membantu pengguna menyelesaikan masalah sistem yang sosfitikated bagi mempercepatkan pengguna menyelesaikan aktivitas kerja harian. Penggunan komputer juga membolehkan penyebaran informasi dilakukan dan memberi hiburan kepada pengguna.

\section{PERKEMBANGAN TEKNOLOGI MULTIMEDIA.}

Tahun 60-an, komputer rangka (main frame computer), digunakan untuk mengendalikan pangkalan data korporat yang besar. 1970-an, terminal komputer digunakan oleh organisasi untuk menyebar dan menguruskan informasi. Era 1980-an, rekayasa komputer diubah dimana ia menjadi lebih mudah digunakan. Semua orang boleh memiliki komputer untuk melakukan kerja-kerja pemprosesan data, game dan sebagainya. 1980-1990-an, perkembangan komputer semakin drastis sehingga mencapai tahap yang tidak tergambar sebelum ini. Dalam masa yang sama, perkembangan teknologi ini telah membawa kepada :

a. Menghasilkan mikro komputer (desktop) dengan kelajuan pemproses yang lebih maju.

b. Meningkatkan kapasitas memori kerja di dalam komputer.

c. Kapasitas memori data yang lebih besar di dalam hardisk dan CD-ROM.

d. Audio dan video digital.

e. Sistem operasi bergrafik memudahkan pengguna menggunakan penunjuk atau klik pada objek dengan menggunakan mouse. Arahan berasaskan antaramuka pengguna bergrafik memudahkan pengguna melakukan proses-proses yang dikehendaki dengan lebih mudah.

f. Rangkaian LAN \& WAN secara meluas membolehkan pengguna berhubung di seluruh dunia.

\subsection{Photoshop.}

Adobe Photoshop disebut Photoshop merupakan perangkat lunak editor citra buatan Adobe Systems dikhususkan untuk pengeditan foto/gambar dan pembuatan efek. Perangkat lunak ini banyak digunakan fotografer digital dan perusahaan iklan sehingga dianggap sebagai pemimpin pasar (market leader) untuk perangkat lunak pengolah gambar/foto, dan, bersama Adobe Acrobat, dianggap sebagai produk terbaik yang pernah diproduksi Adobe Systems. Versi kedelapan aplikasi ini disebut dengan nama Photoshop CS (Creative Suite), versi sembilan disebut Adobe Photoshop CS2, versi sepuluh di sebut Adobe Photoshop CS3, versi kesebelas merupakan Adobe Photoshop CS4, versi keduabelas adalah Adobe Photoshop CS5, versi ketigabelas adalah CS6, dan versi terbaru merupakan Adobe Photoshop CC.

\subsection{Pre \& Pos Tes.}

Pre tes yaitu suatu bentuk pertanyaan, yang dilontarkan guru kepada murid sebelum memulai suatu pelajaran. Pertanyaan yang ditanya adalah materi yang akan diajar pada hari itu 
(materi baru). Pertanyaan itu biasanya dilakukan guru di awal pembukaan pelajaran. Pre test diberikan dengan maksud untuk mengetahui apakah ada diantara murid yang sudah mengetahui mengenai materi yang akan diajarkan. Pre test juga bisa di artikan sebagai kegiatan menguji tingkatan pengetahuan siswa terhadap materi yang akan disampaikan, kegiatan pre test dilakukan sebelum kegiatan pengajaran diberikan. Adapun manfaat dari diadakannya pre test adalah untuk mengetahui kemampuan awal siswa mengenai pelajaran yang disampaikan. Dengan mengetahui kemampuan awal siswa ini, guru akan dapat menentukan cara penyampaian pelajaran yang akan di tempuhnya nanti.

Post test merupakan bentuk pertanyaan yang diberikan setelah pelajaran/materi telah disampaikan. Singkatnya, post test adalah evalausi akhir saat materi yang di ajarkan pada hari itu telah diberikan yang mana seorang guru memberikan post test dengan maksud apakah murid sudah mengerti dan memahami mengenai materi yang baru saja diberikan pada hari itu. Manfaat dari diadakannya post test ini adalah untuk memperoleh gambaran tentang kemampuan yang dicapai setelah berakhirnya penyampaian pelajaran. Hasil post test ini dibandingkan dengan hasil pre test yang telah dilakukan sehingga akan diketahui seberapa jauh efek atau pengaruh dari pengajaran yang telah dilakukan, disamping sekaligus dapat diketahui bagian bagian mana dari bahan pengajaran yang masih belum dipahami oleh sebagian besar siswa.

\subsection{Penyelesaian Masalah.}

Dari permasalahan yang ada ini maka perlu dilakukan pelatihan editing gambar (photo) menggunakan aplikasi yang cukup familiar dikalangan peserta, ini di yakini bisa menambah softskills dan kepercayaan diri alumni SMAN 3 Kota Pagar Alam sehingga tidak hanya masalah atau pelajaran umum saja yang nantinya dipahami tetapi mendapat pelajaran tambahan dalam menghadapi perkembangan zaman pada masyarakat, sehingga menjadi lebih percaya diri.

\section{PEMBAHASAN DAN HASIL.}

3.1. Realisasi \& Pemecahan Masalah.

Rincian pelasanaan kegiatan pengabdian yang dilakukan pada pelatihan ini diawali denga pelaksanaan pre tes untuk mengarahkan narasumber melatih peserta sesuai dengan keperluan pemahaman terhadap aplikasi, berikutnya persiapan praktek karena pada pelatihan ini lebih menekankan pada pemahaman aplikasi adobe photosop secara langsung, penjelasan teori hanya sebagai pengantar pendahuluan agar peserta benar-benar siap melakukan praktek sehingga penjelasan dilakukan secara langsung pada cara menjalankan photoshop, diperkenalkan tools dan fitur yang ada, fungsi dan manfaatnya setelah paham, peserta di minta untuk mengaplikasikan pemahaman secara langsung dalam photoshop yang sudah disiapkan dan melakukan pengolahan data gambar atau pun data video yang sudah peserta miliki, terakhir dilakukan tes lagi yang gunanya untuk mengetahui tingkat keberhasilan pelatihan ini, agar narasumber memahami bagian mana dari bagian pelatihan yang dilakukan belum dipahami oleh peserta. Berikut ini merupakan rincian penjelasan kegiatan dalam bentuk tabel:

Tabel 1. Kegiatan

\begin{tabular}{|c|c|c|}
\hline Waktu & Materi & Penyaji \\
\hline $08.00-09.00$ & Pre Test & \multirow{5}{*}{$\begin{array}{l}\text { Siti Aminah, } \\
\text { Sasmita }\end{array}$} \\
\hline $09.00-09.30$ & Persiapan Membuat Aplikasi pengolah data photo & \\
\hline $09.30-12.00$ & $\begin{array}{l}\text { Panduan Membuat aplikasi dan Tutorial Membuat aplikasi } \\
\text { pengolah data photo }\end{array}$ & \\
\hline $12.00-12.30$ & Ishoma & \\
\hline $12.30-13.00$ & Post-test & \\
\hline
\end{tabular}

Penjelasan tabel 1 merupakan rincian penjelasan dari paragraph sebelumnya yang tujuannya pelatihan dibuat rincian dan acuan yang jelas agar kegiatan pelatihan terlaksana dengan lancar dan terurut sehingga peserta dan pelaksana pelatihan baik dalam memahami langkah penelitian sehingga hasilnya dapat dimenegerti lebih baik oleh yang berkepentingan. Pelatihan dilaksanakan di laboratorium SMAN 3 Kota Pagar Alama dengan menggunakan aplikasi photoshop versi terbaru 
tujuannya untuk memberikan softskills tambahan kepada para peserta karena SMU itu bisanya hanya memberikan pelajaran materi teori yang bersifat umum berbeda dengan SMK yang lebih spesifik sehingga agar peserta lebih percaya diri dan merasa memiliki spesifikasi keahlian atau softskills tambahan maka dilakukan pelatihan ini Karena photoshop bisa diaplikasikan untuk berbagai hal yang berhubungan dengan dunia percetakan, sehingga bila peserta mau berwirausaha dunia percetakan mereka telah memiliki pengetahuan awal sebagai seorang desainer spanduk, baliho dan sebagainya untuk menjadi modal awal, dan keahlian muncul jika sudah benar-benar terjun ke dunia kerja pada saat menemukan permasalahan mereka biasanya menjadi lebih siap dan kompeten, jadi pelatihan ini menjadi landasan awal untuk pembelajaran peserta selanjutnya.

\subsection{Pembahasan \& Hasil.}

Sehingga berdasarkan rincian pelaksanaan pengabdian yang diuraikan diatas maka pembahasan atau uraian hasilnya adalah sebegai berikut:

Tabel 2. Keberhasilan Pelaksanaan Kegiatan

\begin{tabular}{|l|l|}
\hline \multicolumn{1}{|c|}{ Materi } & \multicolumn{1}{c|}{ Hasil } \\
\hline Pendahuluan & $\begin{array}{l}\text { Pendahuluan merupakan kegiatan tes awal untuk mengetahui } \\
\text { pemahaman peseta terhadap aplikasi photoshop. }\end{array}$ \\
\hline $\begin{array}{l}\text { Pengenalan teori pengolahan } \\
\text { gambar, video dan multimedia }\end{array}$ & $\begin{array}{l}\text { Peserta memahami dengan baik teori dan logika pengolahan } \\
\text { data gambar, video dan multimedia. }\end{array}$ \\
\hline $\begin{array}{l}\text { Pengenalan software buat edit } \\
\text { photo dan video }\end{array}$ & $\begin{array}{l}\text { Para peserta menjadi paham software apa saja yang bisa } \\
\text { dimanfaatkan pada saat mengolah gambar dan mampu } \\
\text { mengelompokan berdasarkan fungsi serta manfaat aplikasi } \\
\text { tersebut. }\end{array}$ \\
\hline $\begin{array}{l}\text { Pengenalan tools dan fitur } \\
\text { photoshop }\end{array}$ & $\begin{array}{l}\text { Hasilnya peserta pelatihan mengetahui nama dan fungsi } \\
\text { seluruh tools dan fitur yang ada pada photoshop dan buat apa } \\
\text { aplikasinya/ }\end{array}$ \\
\hline $\begin{array}{l}\text { Memberikan contoh } \\
\text { pengaplikasian fitur photoshop }\end{array}$ & $\begin{array}{l}\text { Peserta pelatihan melihat dan paham bahkan bisa } \\
\text { mengaplikasikan tools yang ada buat mengolah data gambar. }\end{array}$ \\
\hline $\begin{array}{l}\text { Melakukan percobaan aplikasi } \\
\text { atau melakukan edit photo } \\
\text { secara langsung dengan } \\
\text { photoshop }\end{array}$ & $\begin{array}{l}\text { Seluruh peserta bisa mengaplikasikan photoshop untuk } \\
\text { kebutuhannya dan melakukan edit terhadap photo yang } \\
\text { dimiliki dengan hasil baik dan memuaskan. }\end{array}$ \\
\hline Penutup & $\begin{array}{l}\text { Merupakan kegiatan akhir yang dilakukan narasumber } \\
\text { gunanya untuk mengetahui keberhasilan dari pelatihan ini. }\end{array}$ \\
\hline
\end{tabular}

Melalui penjelasan tabel 2 diatas maka dapat diuraikan ulang berdasarkan hasil dari pelaksanaan pengabdian adalah sebagai berikut. Kegiatan pertama pada pengabdian ini adalah pre tes, hasilnya semua peserta belum penah mengolah data photo dengan photoshop walau pun ada pelajaran TIK tetapi mereka belum menggunakan aplikasi photoshop sehingga disimpulkan pelatihan menjadi sangat perlu untuk dilakukan, Kedua pengenalan tool dan fitur dari kegiatan mereka menjadi sangat paham terhadap semua fasilitas yang ada pada photoshop dan mampu memahami fungsinya, sehingga pada tahap ketiga terbukti peserta mampu mengolah dan mengedit data foto yang dimiliki menggunakan photoshop sesuai langkah yang ada pada modul pelatihan dan bimbingan dari narasumber, terakhir dilakukan tes terhadap seluruh peserta dan terbukti dari hasil pengamatan mereka berhasil dan $100 \%$ peserta mampu mengolah data foto,artinya pelaksanaan pelatihan berhasil dan berjalan sesuai dengan harapan penyelenggara, sehingga bisa diidentifikasi berikut merupakan hasil akhirnya, yaitu:

a. Peserta siswa dan siswi SMAN 3 Kota Pagar Alam mempunyai pengetahuan dan pemahaman yang baik tentang multimedia dan pengolahan photo dengan photoshop.

b. Siswa dan siswi SMAN 3 Kota Pagar Alam menjadi sangat paham terhadap teknologi informasi yang lebih aplikatif untuk mendukung dalam pengolahan data yang diperlukannya, missal dalam hal edit photo. 
c. Guru SMAN SMAN 3 Kota Pagar Alam sudah terbantu dalam pemberian pemahaman terhadap teknologi informasi up to date yang aplikatif terutama untuk photoshop.

d. Siswa dan siswi peserta pelatihan lebih memahami lagi tentang aplikasi pembelajaran TIK yang disampaikan oleh guru didalam kelas, jauh lebih memahami secara lebih aplikatif dalam mengolah data gambar menjadi lebih ahli.

e. Siswa siswi peserta pelatihan menjadi lebih merasa percaya diri saat terjun dunia kerja dan lebih memiliki pemahaman pada siswa dan siswi yang melanjutkan studi keperguruan tinggi jelas pembelajaran ini menjadi pemahaman awal dalam bergaul pada perkuliahan di kampus yang sangat kompleks.

\section{KESIMPULAN}

Kesimpulan dari pelaksanaan pengabdian masyarakat $(\mathrm{PkM})$ ini yang dilakukan pada SMAN 3 Kota Pagar Alam bertujuan melatih siswa dan siswi dalam melakukan editing terhadap data gambar atau photo diperoleh kesimpulan sebagai berikut:

a. Membantu para Guru pelajaran TIK dalam hal memahamkan siswa terhadap suatu aplikasi tertentu yang lebih aplikatif.

b. Melaksanakan proses kegiatan pembelajaran dengan cara belajar aplikasi secara langsung ternyata telah mampu meningkatkan semangat siswa belajar menjadi lebih rajin (giat).

c. Mampu meningkatkan rasa percaya diri pada siswa dengan kemampuannya ketika terjun di masyarakat dengan memahami aplikasi yang aplikatif.

d. Mampu menambah softskills siswa-siswi SMAN 3 Kota Pagar Alam yang telah mengikuti pelatihan.

\section{SARAN}

Maka sesuai pemahaman yang dilihat dan dirasakan penulis saat melakukan pengabdian $(\mathrm{PkM})$ ini maka, penulis dalam hal ini bisa memberikan saran:

a. Pelatihan dilakukan dilakukan secara terjadwal, biar kerja sama dengan Pihak SMAN terus terlaksana sehingga STTP bisa lebih dekat dengan calon mahasiswa.

b. Menambah waktu pelaksanaan pengabdian lebih lama sehingga peserta menjadi lebih paham terhadap materi yang diberikan narasumber.

c. Sistem pelaksanaan pengabdian diperbaiki.

\section{UCAPAN TERIMA KASIH}

Terima kasih LPPM.

\section{DAFTAR PUSTAKA}

[1] Menristekdikti. 2016. Panduan Pelaksanaan Penelitian dan Pengabdian Masyarakat di Perguruan Tinggi Edisi X Tahun 2016. hlm. 4

[2] Muslim, B. 2018. Pelatihan aplikasi editing video dengan filmora., Laporan Pengabdian Kepada Masyarakat, LPPM STT Pagaralam.

[3] Muslim, B. 2018. Pelatihan Pembuatan Blog Bagi Guru Ma Ponpes Darul Mutaqin Kota Pagaralam. NGABDIMAS. Vol 1. No.1. Bulan Juni, Hal. 6-11

[4] M.H Jogiyanto, 1995, Pengenalan Komputer, Andi Offset Yogyakarta.

[5] B. Muslim, Pengantar teknologi informasi. Yogyakarta: Deepublish, 2017.

[6] Muslim, B. (2018). Analisis system informasi (SI) terintegrasi di Perguruan Tinggi (PT) (Studi Kasus: STT Pagaralam). Jurnal Teknologi Informasi MURA, Vol 10. Page 83-91.

[7] Muslim, B (2014). Analisis rencana aplikasi teknologi informasi pada STT Pagar Alam. Proseding semnastik dan Magma. Issue: Aplikasi Teknologi dan sistem Informasi. PPP 
UBD Pres. Pages 397-404.

[8] Hutchinson E. Sarah and Sawyer C. Stacey, 2000, Computers, Communications \& Information, McGraw Hill Companies Inc.

[9] Indonesia Services Education HP Tim, 2001, Manajemen Sistem Belajar Di Dunia Maya, Majalah Info Komputer.

[10] Horsley, M., Knight, B., \& Huntly, H. 2010. The role of textbooks and other teaching and learning resources in higher education in Australia: Change and continuity in supporting learning. IARTEM 1-Journal. 3(2). 43-61.

[11] Sadiman, A.S., Rahardjo, R., Haryono, A., \& Rahardjito. 2006. Media pendidikan: Pengertian, pengembangan, dan pemanfaatan. Jakarta: Rajagrafindo Persada.

[12] Isro'Mukti, Y. (2017). Sistem Informasi Madrasah Aliyah Negeri Pagar Alam Berbasis Web. Indonesian Journal of Computer Science, 6(2), 192-205.

[13] Mukti, Y. (2017). Perencanaan Strategis Sistem Informasi Dan Teknologi Informasi Pada Sekolah Menengah Kejuruan Negeri 2 Pagar Alam. JURNAL ILMIAH BETRIK: Besemah Teknologi Informasi dan Komputer, 8(02), 83-92.

[14] Arif, A., \& Mukti, Y. (2017). Rancang Bangun Website Sekolah Menengah Pertama (SMP) Negeri 8 Kota Pagar Alam. JURNAL ILMIAH BETRIK: Besemah Teknologi Informasi dan Komputer, 8(03), 156-165.

[15] Isro'Mukti, Y. (2018, October). Sistem Informasi Manajemen Aset Sekolah Tinggi Teknologi Pagaralam Berbasis Web. In Seminar Nasional Teknologi Informasi dan Komunikasi (SEMNASTIK) (Vol. 1, No. 1, pp. 632-638).

[16] Mukti, Y. (2018). Rancang Bangun Website Sekolah Dengan Metode User Centered Design (UCD). JURNAL ILMIAH BETRIK: Besemah Teknologi Informasi dan Komputer, 9(02), 84-95.

[17] Mukti, Y. (2018). Pelatihan Maintance Komputer SMAN Pagar Gunung. NGABDIMAS, $1(1), 47-51$.

[18] Mukti, Y. I. (2019). Implementasi Jaringan Hotspot Kampus Menggunakan Router Mikrotik. Indonesian Journal of Computer Science, 8(2), 130-138.

[19] Mukti, Y. I., \& Puspita, D. (2019). Sistem Informasi Peringatan Dini Bencana Pada Kota Pagar Alam Berbasis Mobile. Jusikom: Jurnal Sistem Komputer Musirawas, 4(2), 65-74.

[20] Mukti, Y. I. (2019). SISTEM INFORMASI MONITORING KESEHATAN MASYARAKAT BERBASIS WEB MENGGUNAKAN METODE UNIFED MODELLING LANGUAGE. Jusikom: Jurnal Sistem Komputer Musirawas, 4(1), 1-8.

[21] Mukti, Y. I., \& Puspita, D. (2019, December). Web Based Disaster Early Warning System on Pagar Alam City. In Conference SENATIK STT Adisutjipto Yogyakarta (Vol. 5, pp. 309-316).

[22] Isro'Mukti, Y., \& Puspita, D. WEB BASED DISASTER EARLY WARNING SYSTEM ON PAGAR ALAM CITY.

[23] Puspita, D., \& Isro'Mukti, Y. (2019, December). Web-Based Culture Information System of Literature Besemah City of Pagar Alam. In Conference SENATIK STT Adisutjipto Yogyakarta (Vol. 5, pp. 303-308). 